\title{
IOT based Smart Healthcare Wheelchair for Independent Elderly
}

\author{
Prakash Kanade, Jai Prakash Prasad, and Sunay Kanade
}

\begin{abstract}
Notwithstanding adding to the presentation of imaginative innovations and arising business openings in numerous business sectors, improvements in innovation have since brought down labor force requests and working expenses. Likewise, the nature of administrations offered has been upgraded. In this way, as a key empowering innovation for a wide assortment of medical care applications, particularly for the older and handicapped, the Internet of Things (IoT) has as of late acquired extraordinary footing. While IoT-based advancements have started to help the old and incapacitated in numerous parts of their lives and occupations, and IoT helps support the nature of living for the old and crippled, the volume of IoT information produced has risen essentially and surpassed assumptions. An expected option for following their wellbeing status is to make a brilliant wheelchair-based wellbeing checking framework, since it is satisfactory for a more extensive assortment of watchers and, in contrast to wearable gadgets, doesn't need a great deal of support. Shrewd wheelchairs center on the versatility of the unit, yet in addition on observing the patient's prosperity. The point of the current work is to fabricate a shrewd detecting wheelchair through the establishment of sensors inside its structures. The innovation grasped is the Internet of Things, where sensors screen the heartbeat and blood oxygen levels, measure them through implanted frameworks, and move them to the cloud to initiate a trigger in case of any anomaly. The made trigger can be as a SMS or email.
\end{abstract}

Keywords - Arduino, Internet of Things (IoT), LeenaBOT, Raspberry pi.

\section{INTRODUCTION}

The Internet of Things (IoT) can be depicted as an organization of hardware, sensors, network systems administration, and programming inserted things. IoT gives occasions to PC based applications and this present reality for better and smooth coordination. It turns into an illustration of the broader class of digital actual frameworks when enlarged with sensors and actuators, in light of the fact that everything is exclusively conspicuous and can interoperate inside the current organization foundation. It is anticipated that the IoT will comprise of billions of relics in a couple of years, while the IoT brings about expanded execution, exactness, and financial advantages. Contingent upon the gadget details, IoT executions make it simple to catch a wide range of data from a couple of bytes to numerous megabytes.

In contrast to customary telemetry applications, convenient information will at present be conveyed to buyers

Submitted on August 14, 2021.

Published on September 13, 2021.

Prakash Kanade, Hobby Researcher in Robotics, Artificial Intelligence, IOT, USA.

(e-mail: Prakashsrs@ ${ }^{@}$ gmail.com) through IoT administrations. In such manner, since harmed individuals don't bear to fly, keen medical care administrations help them access medical care offices, the IoT is a noteworthy method for offering free living alternatives and assisting with improving their personal satisfaction. IoT frameworks can hypothetically give a scope of independent choices for living, for example, observing front entryways and lighting, which can furnish customers with personal satisfaction and significant serenity for parental figures.

Shrewd home frameworks, perhaps the most well-known IoT organization areas, have started giving various occasions to individuals with handicaps to live more freely over the most recent few decades. Individuals with incapacities deal with home programming, can turn on and off lights, and can sort out who is hitting against the entryway by utilizing savvy home arrangements. Most houses were not built considering people with inabilities; along these lines, since the switches are outside their ability to control, certain individuals can't kill the lights on and. For people who utilize an electric wheelchair, despite the fact that the switches are more modest than ordinary, they are still high. In this manner, individuals with incapacities ordinarily depend on another person. Nonetheless, on account of novel IoT-based innovations, in the event that they have Internet-associated lighting that can be worked utilizing PDAs, they can turn the lights on and off. You may utilize cell phones to kill on and a story fan, control warming and ventilation, or utilize a voice-initiated TV manual for change channels. Additionally, individuals with strolling inabilities at this point don't have to answer the entryway and they can open the locks naturally and welcome their guests in as opposed to doing as such. Because of the way home robotization frameworks have been assembled, it is conceivable to work practically all home machines from a focal unit. Indeed, even by considering their purchasers' ordinary exercises, shrewd homes can begin finding out about themselves. This is especially useful for people who experience difficulty planning their timetables or are experiencing cognitive decline. To summarize, there are numerous potential focal points and sensible utilizations of savvy home advances.

The focal factor in the plan of assistive homegrown projects is crisis help and reaction frameworks [1]. Individual admonition frameworks and crisis ready telephones [2] are the original of crisis help and reaction frameworks. In this age, a standard arrangement comprises of a small remote pendant handset and a focal unit, with a
Dr Jai Prakash Prasad, Professor, Don Bosco Institute of Technology, Bangalore, India

(e-mail: Jaiaasu@gmail.com)

Sunay Kanade, Student, LeenaBOT Robotics Pvt Ltd, USA

(e-mail: Sunaykanade6@ gmail.com) 
mouthpiece and amplifier, connected to a telephone port. An all day, everyday control focus that has any insights regarding the controlled client, for example, ailments and sensitivities to drugs, is named whether the pendant is set off. The control place at that point converses with the individual being followed to choose whether the person needs help. Crisis assets are dispatched where backing is mentioned.

Since a portion of the matured and debilitated rely entirely upon their relatives for their mindful necessities, the passionate weight of their family parental figures can be huge. Adaptable and practical answers for fulfill this interest are thusly required. For the majority of the low to medium level disability cases, manual or electric wheelchairs are fulfilling where individuals can utilize the wheelchair freely. In such conditions, wheelchair clients here and there need independent versatility and depend on another person to work the wheelchair. As found in Fig. 1, study including wheelchairs looks to fabricate keen wheelchairs to tackle those issues. The point of the proposed Smart Sensing Wheelchair is to intermittently identify any patient's cardiovascular irregularity and to alarm the individual worried by methods for a message [3], [4].

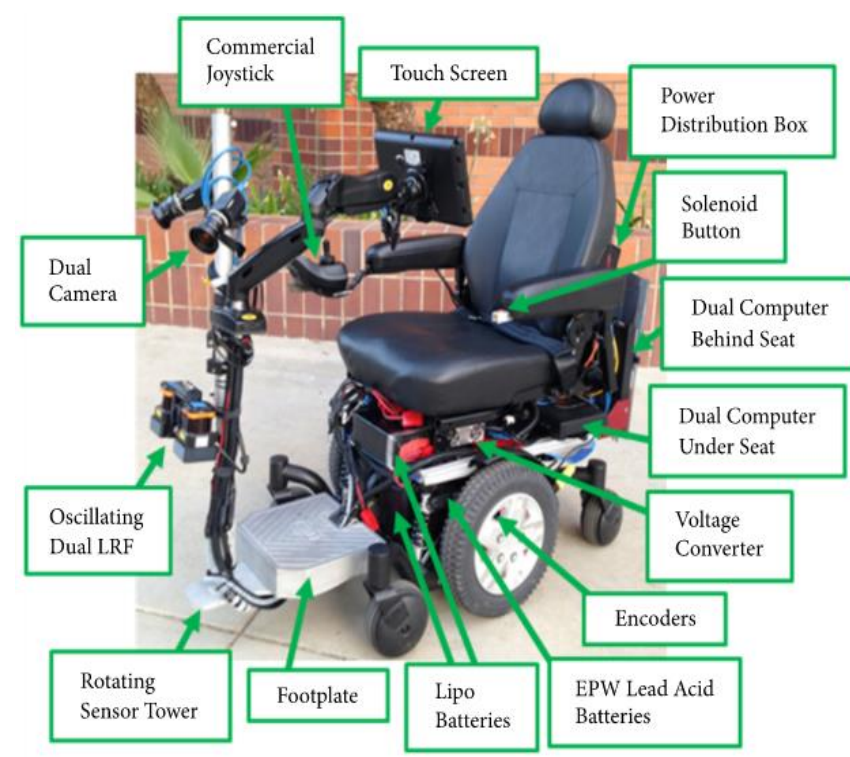

Fig. 1. Assistive Wheelchair.

\section{LITERATURE REVIEW}

Helbostad et al. [5] is a structure that accumulates buyer information utilizing cell phones and wristbands and decides potential danger factors relying upon their activities. The data of the clients is caught both indoor and outside and, contingent upon these outcomes, an intercession gadget distinguishes when the individual has a medical issue and requires outer accomplices, for example, geriatricians or guardians to meddle. As the structure is secluded, this methodology can be executed in a city-wide setting.

Kamali et al. [9] to energize safe maturing, the project looks to construct an earth shattering multidimensional, modified training framework. By giving those tips and suggestions to a better way of life dependent on the information gathered from their regular day to day existences, this gadget helps older individuals. The undertaking makes a virtual modified mentor utilizing the gathered information, which gives exhortation to upgrade the prosperity of the inhabitant.

Khadraoui et al. [11] proposes a captivating technique zeroed in on ICT apparatuses to gather data on old individuals and make suggestions on what is the correct way to follow when they choose to traverse the district. These schedules depend on the limits of the buyers and consider their actual necessities. To help customers in their excursions, the stage utilizes a versatile PC. The undertaking considers open regions as it were. In a city-wide foundation, this activity does not since the task is intended to be utilized exclusively by a couple of individuals.

Mihovska et al. [12] is a "brilliant divider" project. This divider gives reports on the wellbeing condition of the client being followed, giving continuous data on his/her expert conduct, for example, cardiopulmonary manifestations or neuromuscular developments. The key objective is to energize old residents' free living by gathering information in an indoor air with respect to their medical issue. This activity, in any case, doesn't catch information from open spaces, nor does it consider the cravings and achievement of more established individuals when leading outside exercises.

Astaras et al. [14] is a task that has a few equals to the open-source-based arrangements in the CASA project. The point of the venture is to acquire information from older individuals in their home setting by utilizing just IoT-based minimal effort arrangements. Information acquired was utilized to make a modified profile to get refreshes about how to advance their daily routines and advance indented experiencing. This strategy is essentially founded on gathering information from indoor spaces as opposed to outside spaces. The task is in this manner not intended to be adaptable in a city-wide setting.

Stavrotheodoros et al. [18] venture acquaints an intelligent framework with incorporate the semantic interoperability of dynamic and stable matured IoT organizations. Focused on IoT arrangements, the venture incorporates a scope of different layers to catch information from occupants and trade it with outsiders utilizing the ideas of Connected Open Data. The venture's focal idea is to establish a scholarly climate to lighten tricky conditions and secure the personal satisfaction of senior individuals by giving them an approach to be autonomous of themselves.

Santander et al. [19] is an undertaking centered in the district. This activity intends to improve the prosperity of Santander individuals by gathering information in an unpretentious manner. The undertaking utilizes a scope of different ICT arrangements, for example, movement sensors, NFC, GPS or QR codes, to catch information from individuals in indoor and outside conditions. Besides, this venture includes a module that can transform the information gathered into semantic information to be traded with outsiders and endeavor to discover novel thoughts that can upgrade the life of the inhabitant of Santander.

Fenton et al. [20] is an exertion of the Municipality of Odense and the University of Southern Denmark to better the lives of the individuals of Odense. Besides, the activity screens the most burdened individuals to know whether measures are required and to quantify the markers that 
distinguish in the event that they are in danger of being taken out from the gathering. This activity has equals to Smart Santander, it rather catches information from outside spaces.

\section{SYSTEM DESIGN}

As found in Fig. 2, the framework is disintegrated into segments and assessed to perceive how well those segments work and speak with one another.

The IOT edge framework is required on the customer side. An Arduino stage is required on the worker side. In connecting current machines to an IOT cloud organization, the IOT edge gadgets uphold. They are chiefly inserted equipment parts that have a working climate for running custom projects for:

- Connected Devices Interfacing.

- Boundaries or signs for perusing from joined gadgets.

- Interfacing with the web.

- Information conveyance to an IOT worker.

- Information recovery from an IOT cloud.

- Facilitating neighborhood endpoints from an IOT cloud for tolerating demands.

- Imparting signs and checking the gadgets related.

1. Arduino Platform: The Arduino is a mode for the making of machines that can feel the genuine climate and screen it. The IOT cloud network is the essential capacity that goes under this.

2. IOT cloud platform: IOT cloud administrations are a particular private or public cloud-based framework that is a broad subject in itself. Deliberately planned IOT cloud frameworks for use by edge clients. The accompanying crucial administrations are for the most part offered by the IOT stages:

- Electronic authoritative comfort for the control of edge interface association information. Regularly known as channels are client explicit association focuses, in spite of the fact that there are likewise conventional message lines on which information can be posted from any gadget.
- To store the approaching framework information, cloud-based backend information bases.

- Cloud-put together investigation frameworks work with respect to approaching information and transform the information into alluring ways that are more important.

The following are the attributes of the gadget being proposed:

- The production of a brilliant wheelchair that controls prosperity and utilizations the heart mood to analyze any physiological irregularity and furthermore tests the degree of blood oxygen utilizing beat oximetry sensors.

- On the rundown, the data is changed and if any variation from the norm is recognized, it will caution the individual worried by messages/sms. The objective of the patient is to get the machine in a standard wheelchair if there should be an occurrence of anomaly and caution guardians.

- The beat identified by the PPG sensors and the SPO2 sensors (fringe narrow oxygen immersion) is the information. On the OLED board, the yield of the PPG diagram is appeared while Cayenne demonstrates the yield of the beats every moment.

3. General Constraints

- The sensors ought not to move a great deal and they ought to be effectively positioned to get the specific qualities.

- As the handled information is shipped off the cloud and a sign for email/sms is made, a decent Wi-Fi connection ought to be conceivable.

- The shopper ought to have a PC dynamic to turn the trigger conditions on/off.

4. Software and Hardware Requirements

The software requirements are:

- Arduino;

- Window PC/OS;

- Arduino IDE;

- MQTT Library;

- Max30100 library.

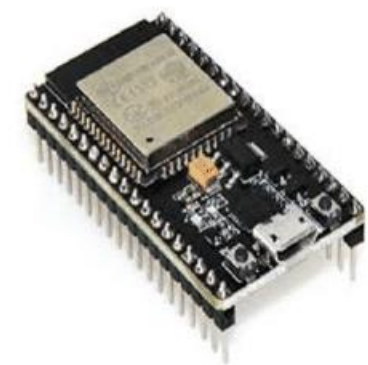

(a)

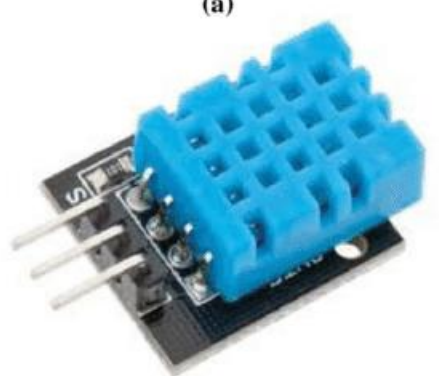

(d)

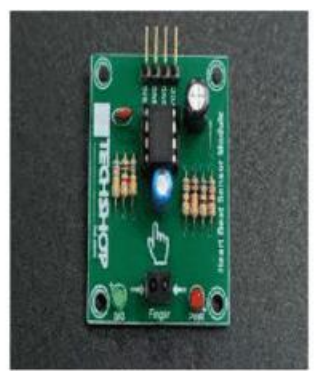

(b)

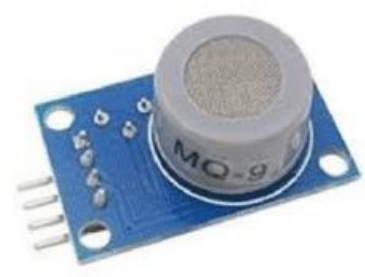

(e)

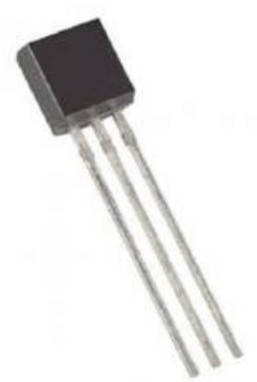

(c)

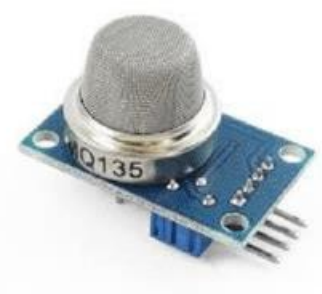

(f)

Fig. 2. The hardware components for the healthcare monitoring system. a. ESP32 b. heartbeat sensor c. body temperature sensor d. room temperature sensor e. CO sensor f. $\mathrm{CO}_{2}$ sensor [22]. 
The hardware requirements are:

- Arduino Nano;

- Laptop Configuration;

- Node MCU;

- SpO2 Sensor;

- PPG sensor;

- 4.7k ohm resistance;

- SSD 1306 OLED display-128*64.

5. Non-Functional Requirements,

- Performance Requirements: Stable web association is needed by the plan.

- Reliability: At any time, the gadget can be utilized from any scene.

\section{PROPOSED SYSTEM}

The proposed system is shown in Fig. 3.

As found in Fig. 3, the arranged gadget means to be a minimal effort shrewd wheel seat.

- As far as prosperity screening and alarming in case of pulse and respiratory rate anomalies, it is astute.

- By estimating the heartbeat and respiratory rate, wellbeing screening will be done.

- Normal (grown-up) pulse - 60-100 bpm.

- Common (grown-up) respiratory rate-12-20 breaths for every moment.

- Any gross disparity will be a pointer of a basic sickness from this set.
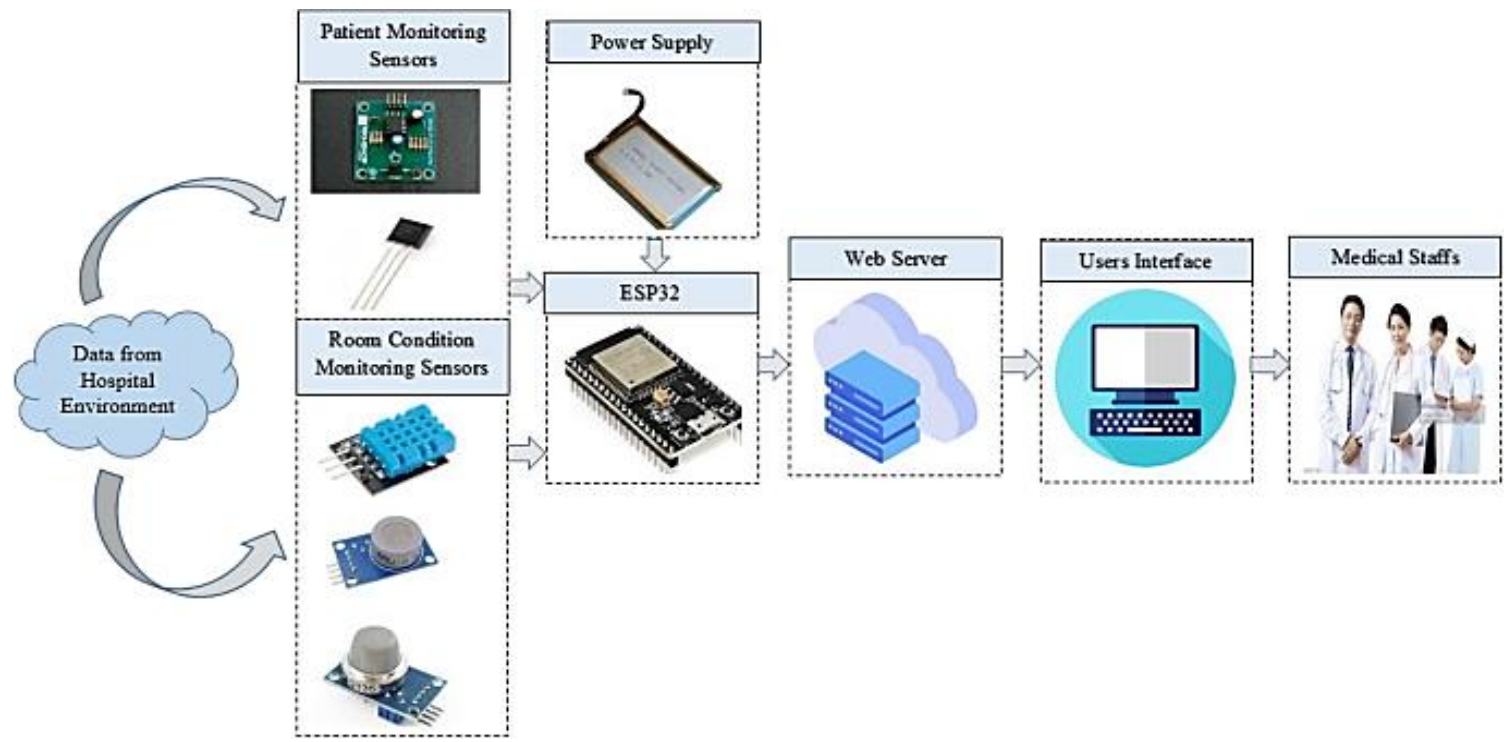

Fig. 3. Proposed System Block Diagram.

\section{IMPLEMENTATIONS AND RESULTS}

In various settings, the setup technique as found in Fig. 4 was checked with various subjects of various ages. In the experiments, we physically estimated the genuine worth and noticed an incentive from the current technique for heartbeat, internal heat level, and room temperature sensors. Here, the room temperature sensor is utilized primarily for dampness estimations. From the outcomes, we determined the pace of blunder to exhibit the framework's adequacy. As there is no elective method to compute the measure of toxic gases, the MQ-9 and MQ-135 information are appeared on
- The heart cadence is identified by PPG Sensors.

- The PPG Sensor yield is provided for handling to the microcontroller gadget.

- Inside the microcontroller, the pulse signal is put away.

- For typical conditions, the heart musicality is under a fixed limit inside that age gathering.

- To analyze any heartbeat anomaly, for example, Tachycardia (resting pulse $>100 \mathrm{bpm}$ for grown-ups over 15 years), the sign is broken down.

- An irregularity might be known as a more noteworthy or below the norm resting heartbeat.

- To distinguish the respiratory rate, the thermistor is utilized as a breath sensor.

- The breath sensor yield is given to the handling microcontroller gadget.

- For the ID of peculiarities from ordinary, the sign is broken down.

- In the microcontroller, cell numbers are coded to be recipients of the notice call.

- A pre-set admonition message is shipped off the predefined cell numbers by means of the GSM Module, which is connected to the microcontroller board, when any anomaly is noticed.

- The message is shipped off the beneficiaries by means of the GSM network as a SMS, accordingly, making them aware of beware of the patient.

- To have a few recipients for the post, the gadget will be modified. 
TABLE II: OBSERVATION OF BODY TEMPERATURE

\begin{tabular}{ccc} 
Sample & Actual & Observed \\
\hline 1 & 96.2 & 96.7 \\
2 & 97.3 & 96.6 \\
3 & 97 & 97.5 \\
4 & 95.8 & 96.4 \\
5 & 96.4 & 96 \\
6 & 97.1 & 95.9 \\
\hline
\end{tabular}

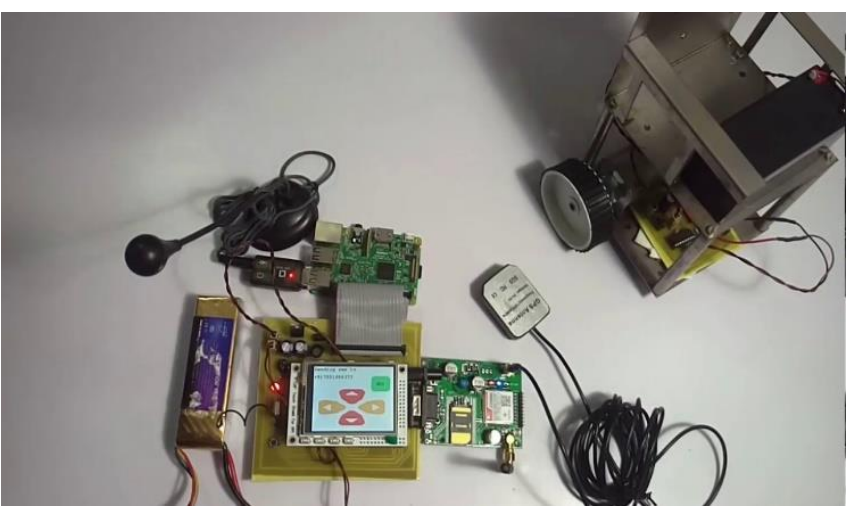

Fig. 4. Smart wheelchair developed system.

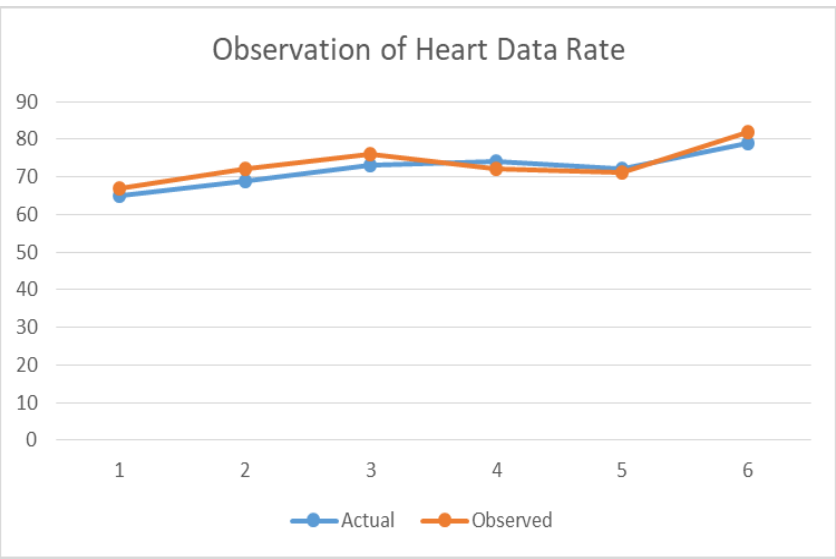

Fig. 5. Observation of Heart Data Rate

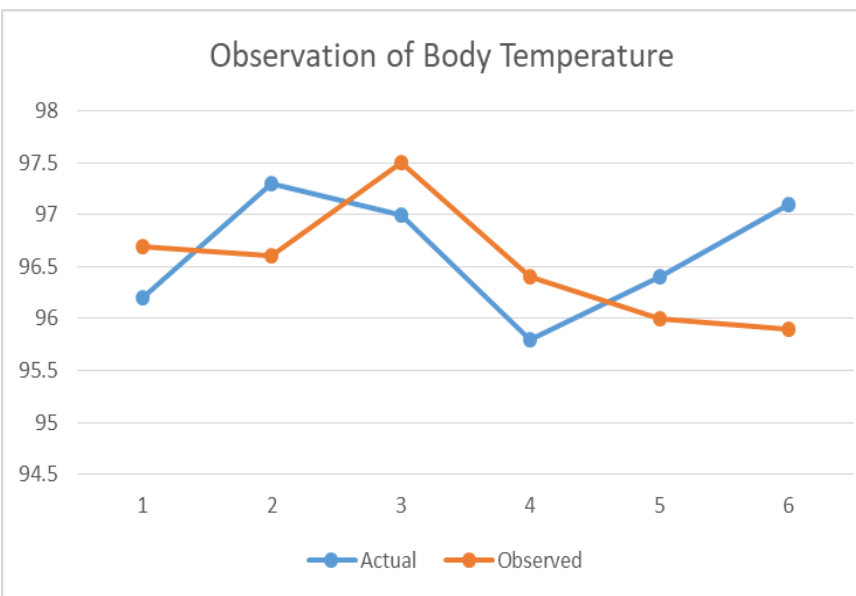

Fig. 6. Observation of Body Temperature.

\section{CONCLUSION}

This work intends to make a reasonable brilliant wheelchair by joining a wellbeing observing gadget based on a microcontroller into a standard wheelchair, utilizing pulse to recognize any cardio vascular anomaly. Cautions by sending the alarm signal across the remote organization to determine cell phones/email-id of clients. This work is brought out through the establishment of sensors inside its system to make a brilliant wheelchair dependent on a customary one. The focused-on sensors are beats where the armrests are the focused on interface structures. The objective was to make a moderate and simple to-utilize wheelchair wellbeing global positioning framework that causes patients with incapacities to be in contact with the individual required through SMS warnings. The patient local area will at that point monitor the patient's prosperity by detecting the heartbeat, breaking down the information and sending the data to the cloud.

\section{REFERENCES}

[1] B. Farahani, F. Firouzi, V. Chang, M. Badaroglu, N. Constant, K Mankodiya, towards fog-driven IoT eHealth: Promises and challenges of IoT in medicine and healthcare, Future Gener. Comput. Syst., 2018, 78, 659-676.

[2] Alsibai, Mohammed Hayyan \& Sibai, Al \& Abdul Manap, Sulastri. (2015). A Study on Smart Wheelchair Systems. 4 10.15282/ijets.4.2015.1.4.1033.

[3] M.N.K. Boulos, N.M. Al-Shorbaji, On the Internet of Things, smart cities and the WHO Healthy Cities, 2014.

[4] Divya Jennifer et al, IOT based Smart Sensing Wheelchair to Assist in Healthcare, International Research Journal of Engineering and Technology (IRJET), Vol. 6, Issue 6, June 2019.

[5] J. L. Helbostad, B. Vereijken, C. Becker, C. Todd, K. Taraldsen, M. Pijnappels, K. Aminian, S. Mellone, Mobile health applications to promote active and healthy ageing, Sensors, 2017, 17 (3), 622.

[6] A Study on Smart Wheelchair Systems, International Journal of Engineering Technology and Sciences (IJETS), Vol. 4 (1), December 2015 .

[7] E. Pippa, I. Mporas, V. Megalooi konomou, Feature selection evaluation for light human motion identification in frailty monitoring system, in: ICT4AgeingWell, 2016, pp. 88-95.

[8] Smart Wheelchair: Integration of multiple Sensors; IOP Conf. Series: Materials Science and Engineering, 254, 2017, 072008.

[9] M. El Kamali, L. Angelini, M. Caon, G. Andreoni, O.A. Khaled, E. Mugellini, Towards the NESTORE e-Coach: a tangible and embodied conversational agent for older adults, in: Proceedings of the 2018 ACM International Joint Conference and 2018 International Symposium on Pervasive and Ubiquitous Computing and Wearable Computers, ACM, 2018, pp. 1656-1663.

[10] D. Khadraoui, H. Ayed, D. Nicolas, Sustainable E 2 mobility services for elderly people - Platform system architecture, in: Science and Information Conference, SAI, IEEE, 2014, pp. 943-948.

[11] A. Mihovska, S.A. Kyriazakos, R. Prasad, eWALL for active long living: Assistive ICT services for chronically ill and elderly citizens, in: Systems, Man and Cybernetics, SMC, 2014 IEEE International Conference on, IEEE, 2014, pp. 2204-2209.

[12] M. H. Purnomo, Y. Kristian, E. Setyati, U. Delfana Rosiani and E. I. Setiawan, "Limitless possibilities of pervasive biomedical engineering: Directing the implementation of affective computing on automatic health monitoring system," $20168^{\text {th }}$ Internationa Conference on Information Technology and Electrical Engineering (ICITEE), Yogyakarta, 2016, pp. 1-4

[13] A. Astaras, H. Lewy, C. James, A. Katasonov, D. Ruschin, P. Bamidis, Unobtrusive Smart Environments for Independent Living and the Role of Mixed Methods in Elderly Healthcare Delivery: The USEFIL Approach, Health Care Delivery and Clinical Science, IGI Global, pp. 1307-1324, 2017.

[14] S. U. UPase, Speech recognition based robotic system of wheelchair for disable people, 2016 International Conference on Communication and Electronics Systems (ICCES), Coimbatore, 2016, pp. 1-5.

[15] A.N. Belbachir, M. Litzenberger, S. Schraml, M. Hofstätter, D. Bauer, P. Schön, M. Merne, and CARE: A dynamic stereo vision sensor system for fall detection, in: Circuits and Systems, ISCAS, 2012 IEEE International Symposium on, IEEE, 2012, pp. 731-734.

[16] S. Stavrotheodoros, N. Kaklanis, K. Votis, D. Tzovaras, A smarthome IoT infrastructure for the support of independent living of older adults, in: IFIP International Conference on Artificial Intelligence Applications and Innovations, Springer, Cham, 2018, pp. 238-249.

[17] L. Sanchez, L. Muñoz, J.A. Galache, P. Sotres, J.R. Santana, V Gutierrez, D. Pfisterer, SmartSantander: IoT experimentation over a smart city testbed, Comput. Netw., 2014, 61, 217-238. 
[18] P. Fenton, Sustainable mobility in the low carbon city: Digging up the highway in Odense, Denmark, Sustainable Cities Soc., 2017, 29, 203 210 .

[19] J. Kim et al., Assessment of the Tongue-Drive System Using a Computer, a Smartphone, and a Powered-Wheelchair by People with Tetraplegia, in IEEE Transactions on Neural Systems and Rehabilitation Engineering, vol. 24, no. 1, pp. 68-78, Jan. 2016.

[20] Prakash Kanade, Sunay Kanade, Medical Assistant Robot ARM for COVID-19 Patients Treatment - A Raspberry Pi Project, International Research Journal of Engineering and Technology (IRJET), vol. 7, no. 10, pp. 105-111, 2020.

[21] Prakash Kanade, Monis Akhtar, Fortune David, Remote Monitoring Technology for COVID-19 Patients, European Journal of Electrical Engineering and Computer Science, vol. 5, no. 1, pp. 44-47, 2021.

[22] Prakash Kanade, Monis Akhtar, Fortune David, Computer Networking and Technology Improvement in the Age of COVID-19, International Journal of Advanced Networking and Applications (IJANA), vol. 12, no. 03, pp. 4592-4595, 2020. 